\title{
Regional analytics and forecasting for most affected stock markets: The case of GCC stock markets during COVID-19 pandemic
}

\author{
Khalid Alkhatib $^{1} \cdot$ Mothanna Almahmood $^{1} \cdot$ Omar Elayan $^{1} \cdot$ Laith Abualigah $^{2,3}$ (D)
}

Received: 23 July 2021/Revised: 11 September 2021 / Accepted: 26 September 2021/Published online: 17 October 2021 (C) The Society for Reliability Engineering, Quality and Operations Management (SREQOM), India and The Division of Operation and Maintenance, Lulea University of Technology, Sweden 2021

\begin{abstract}
This paper determines the most affected stock market by COVID-19 among GCC stock markets and extracts the factors that increase this effect. Recommendations from the analytics results are studied, which can mitigate the financial impacts by taking the proper actions to reduce them. Despite the actions taken by countries worldwide to prevent the spread of COVID-19, the financial effects are still unidentified. Recently, the spread of the COVID-19 caused a decline in the stock market indicators because most sectors witnessed a recession because of curfews imposed to limit the spread of the virus. Different datasets are collected from the "Trading Economics" website, related to the indicators of COVID-19 and stock markets for each Gulf Cooperation Council (GCC) country. In addition, constructing visualizations of the most critical factors that support the facts extracted from the correlation analytics results showed that Bahrain was most affected by the COVID-19 pandemic with 47,351 confirmed cases per
\end{abstract}

Khalid Alkhatib

khatib@just.edu.jo

$\triangle$ Laith Abualigah

Aligah.2020@gmail.com

Mothanna Almahmood

Mr.mothanna@gmail.com

Omar Elayan

Onelayan18@cit.just.edu.jo

1 Computer Information System Department, University of Science and Technology, Irbid, Jordan

2 Faculty of Computer Sciences and Informatics, Amman Arab University, Amman 11953, Jordan

3 School of Computer Sciences, Universiti Sains Malaysia, 11800 Pulau Pinang, Malaysia million populations. Moreover, building a forecasting model using Artificial Neural Network to establish how the virus will continue spreading until the end of May 2020. The results showed that the Kuwait stock market was the most affected by the pandemic, with average losses of -0.28 . The losses would soon increase in the Bahrain stock market by -0.29 , so in the next two months, the losses would be $-0.35 \%$, and Bahrain would be the most affected market in GCC.

Keywords COVID-19 - Stock markets - Gulf cooperation council · Forecasting

$\begin{array}{ll}\text { Abbreviations } \\ \text { GCC } & \text { Gulf cooperation council } \\ \text { UAE } & \text { United Arab Emirates } \\ \text { KSA } & \text { Saudi Arabia } \\ \text { FPA } & \text { Flower pollination algorithm } \\ \text { ANN } & \text { Artificial neural network } \\ \text { MENA } & \text { The Middle East and North Africa } \\ \text { SSA } & \text { Salp swarm algorithm } \\ \text { MLP } & \text { Deep learning structures }\end{array}$

\section{Introduction}

By the middle of April 2020, more than two million COVID-19 cases were recorded worldwide. Coronavirus is an emerging disease where there is limited information on a cure for the near future (Ronald Doni et al. 2021; Sharma et al. 2021). Moreover, it has a high speed of spread and expansion, which led to a massive increase in the number 
of new active cases daily. COVID-19 has started in Wuhan, China. Then spread to European countries and the Middle East, notable countries of the GCC region (Mottahedi et al. 2021).

GCC countries are the United Arab Emirates (UAE), Saudi Arabia (KSA), Qatar, Oman, Kuwait, and Bahrain (Bekhet et al. 2017). The GCC is the most economically stable in the Middle East and North Africa (MENA) region, whose economy depends on the oil production industries, characterized by developing their economic structures and high living standards (Davison 1960; Alber and Saleh 2020). Global stock markets witnessed more impact by the covid-19 pandemic than any previous pandemic, even the Spanish flu (Baker et al. 2020). However, in the GCC, the unprecedented outbreak of COVID-19 has led to instability in the region (Ben Amar et al. 2020). The cause was not marked by the increase in the number of infected cases (Sadiq et al. 2021; Rubbaniy et al. 2021). However, instead, actions are taken to prevent the pandemic's spread. Governments were quick to take preventive actions, negatively affecting various sectors, namely service, tourism, and financial. In turn, this caused panic for the public and increased their concern over the ability of the leadership response to deal with the crisis appropriately. However, the GCC countries have the strongest economies in the Arab world and are most affected. Furthermore, the actions taken to prevent the COVID-19 spread resulted in a decline in the stock markets' profit gains.

The impact on the stock market depends entirely on the extent of Covid-19 spread and how governments respond to take preventive actions that protect their economies (Szczygielski et al. 2021; Okorie and Lin 2021). However, this paper was conducted to answer the question of what if the situation remains, and aim to determine the most affected stock market and to reveal the possible complications of the crisis in the short term in order to extract accurate knowledge that helps decision-makers in developing new recommendations to limit the risky impact - this work based on the use of different datasets that collected from the "Trading Economies" website. The first dataset contains the number of confirmed cases (per day) from January to October 2020. The second dataset contains the sum of the daily points of the stock markets during the same period. The third dataset contains the most important economic and social features that indicate the general state of countries.

The work methodology analyzes the correlation between the number of confirmed virus cases and the number of points the stock market has acquired per day. Then visualizing the distributions of the economic and social factors, in which the interpretations support the extracted facts from the correlational analytics results. Finally, building a forecasting model using ANN techniques to summarize the pandemic spread until the end of December. The article's origination is as follows, section two shows the literature review, and section three shows the research methodology. In contrast, section four reveals the experimental results, wherein section five is the conclusion. Thus, this paper is vital to show the main effects that happed by COVID-19 on stock marketing and business. Also, it shows how the effects carried alongside the spread of the COVID-19 pandemic over various businesses. The structure of this paper is organized as follows. Section 2 shows the related works. Section 3 shows the proposed method. Section 4 illustrated the experimental results. Finally, the conclusions and future works are given in Sect. 5 .

\section{Literature review}

Following the spread of the pandemic globally, many researchers studied the fields that were suffering from COVID-19. Moreover, many research papers have been published in the literature to study the effects of the COVID-19 on various aspects (Abualigah et al. 2021; Sumari et al. 2021; Yousri et al. 2021; Shehab et al. 2019). Therefore, this paper (Gormsen and Koijen 2020) has conducted a predictive paper on future stock prices for America and European Union employing a simple forecasting model. They use data from the entire stock exchanges and total profit contracts, where their results summarized as of April 3; their annual growth forecast in dividends is down $27 \%$ within the US and $37 \%$ within the EU. The forecast for GDP growth is down by $6.1 \%$ within the US and $8.2 \%$ within the EU. As well as the boundary on the change in expected dividends is $-45 \%$ within the US and $-58 \%$ within the EU at the 2-year horizon, these percentages and results express the extent of the significant damage suffered by the countries due to Covid-19 and the negative impact it has on the economic field.

Also, in the paper (Liu et al. 2020), the researchers have conducted an analytical paper on the impact of the emergence of the emerging Covid-19 on the stock exchange through 21 significant indicators by targeting the stock exchange within the most affected countries like Japan, Korea, Singapore, the US, Germany, Italy, and the UK. Using the event paper results, the researchers found that the financial markets decreased significantly within the most affected countries, where the disease spread rapidly and significantly. Besides, Asia's countries witnessed more damage than others, as their results were sudden and more harmful than others. The results also indicated an enormous challenge that the financial institution will face, as most companies are heading in two ways, either reducing the number of employees to a minimal number or completely close down. Additionally, investor fears caused by 
instability, especially in Asia, express the extent of the countries' damage due to COVID-19. Therefore, the negative impact is on the economic field.

In this paper (McKibbin and Fernando 2020), the researchers have conducted an exploratory and predictive paper on what will be the case with the economic situation within the coming year if the COVID-19 continues to spread and become a worldwide pandemic. They created seven scenarios during the pandemic, examined the results of scenarios using the modeling technique. The results also indicated that it could significantly affect the worldwide economy within the short term if the present situation continues without about the seven scenarios. The aim was to supply information on a range of potential economic costs of the disease. The researchers found that various policy responses were needed within the short term and in the coming years. Within the short term, central banks and Treasury bonds must confirm that dysfunctional economies still function. At the same time, the outbreak of COVID-19 continues.

Additionally, there is a critical role for governments (Sherif 2020; Alber and Arafa 2020). While reducing interest rates may be a possible response for central banks, the shock is a demand management problem and a multifaceted crisis that will require monetary, fiscal, and health policy responses. Quarantining affected people and reducing large-scale social interaction is an efficient response (Al Refai et al. 2021; Adekoya et al. 2021).

The paper has studied different regression approaches for modeling the prevalence of coronavirus and its effect on the stock market, as the logistic curve model used with Bayesian regression for predictive analytics of the COVID19 spread. The effect of COVID-19 was studied employing a regression approach and compared to the effect of other crises. In practical analyses, it is essential to seek out the maximum number of coronavirus cases per day, now half the estimated coronavirus spread within the area under investigation. The results revealed that different crises for various reasons have a particular effect on an equivalent stock. It is essential to research its effect separately. Bayesian reasoning makes it possible to research the uncertainty of the consequences of the crisis.

Predictive studies were not limited to stock and financial prices, some others predicting upcoming cases. The researchers in paper (Al-qaness et al. 2020) have undertaken a predictive paper on estimating and forecasting the number of confirmed cases with coronavirus within the next ten days by introducing a new prediction model based on previously confirmed cases registered only in China. The model used is an improved adaptive neuro-fuzzy inference system (ANFIS) using an enhanced flower pollination algorithm (FPA) by using the Salp Swarm Algorithm (SSA). In general, SSA is employed to improve FPA to avoid its drawbacks. Researchers tested the proposed predictive model with two different data sets, one for America and China, of confirmed weekly flu cases in the two countries. The results indicated reassurance regarding the proposed model.

In the paper (Gupta et al. 2020), the researchers have conducted an analytical and predictive paper using two models of machine learning, SIER, and regression to research the prevalence of Covid-19 and predict the infected number of cases expected to be infected within a subsequent two weeks. Evaluating the model performance using RMSLE achieved 1.52 for the SEIR model and 1.75 for the regression model. The RMSLE error rate was found between the SEIR model and the regression model 2.01. Also, the worth of R0 is the spread of the disease calculated to be 2.02 . They also found that the expected cases might rise from five to six thousand within the next 2 weeks. The research aimed to supply enough information for the state of India and doctors to take the necessary measures and the required precautions within the coming days.

Researchers have attempted to enhance the available information with more comprehensive information about the emerging disease COVID-19, which still knows little about treating it. In the paper (Sohrabi et al. 2020), the researchers have conducted research that provided all the information a person needs to know about the emerging disease Covid-19, including methods dealing with the disease, clarifying its transmission speed, and preventive measures. Besides, numbers and the geographical areas where the disease spread. They also pointed out that quarantine alone is not enough to prevent disease, but must also be strict and continuous monitoring to track the adaptation and development of the infected and his ability to transfer and predict in the future where these factors will play a vital role in the diagnosis of individuals and mortality.

In the paper ( $\mathrm{Li}$ et al. 2019), the researchers have conducted extensive COVID 19 to clarify the following mechanisms that cause diseases and epidemiological characteristics, identify potential drug targets, and finally, pathogens. The aim was to develop effective strategies for prevention and treatment, as researchers suggested some drugs that might fulfill the purpose of contributing to the treatment of Covid-19. They summarized the importance of isolating patients and adopting preventive measures as it successfully reduced the disease. The researchers in paper (Reyad 2003) also undertook research. They provided descriptive information about the emerging disease COVID-19 and its effect on the Arab countries, especially those who carried out the strike and may provide some predictions in weeks. 
In the paper (Rosenzweig 2015), the researchers have conducted a predictive paper to predict the stock market's movement. They proposed a new prediction algorithm that takes advantage of the temporal link between global stock markets and various financial products to predict stocks' direction in the coming day. The same algorithm also examined several other regression algorithms to monitor the actual increase in the market. They created a simple trading model to see the performance of the proposed prediction algorithm against other criteria. The accuracy results for the numerical prediction indicated a $74.4 \%$ prediction accuracy in the NASDAQ, $76 \%$ in the $\mathrm{S} \&$ P500. The data collected from different global financial markets were examined through the proposed model. The results summarized in three critical points, correlation analysis indicates the strong relationship between the US stock index and global markets that closed before or when trading in the United States. Models suggested variety relies on machine learning to predict the daily trend of American stocks. The numerical results suggested high accuracy and a practical trading model based on our welltrained forecast. The model gave a higher profit than the specified criteria.

In the paper (Hiransha et al. 2018), the researchers have conducted a predictive paper on future stock prices based on historical stock prices, using four types of deep learning structures (MLP), (RNN), (LSTM), and (CNN). They used the closing price of two different markets, the New York Stock Exchange (NYSE) and the National Stock Exchange of India (NSE), where the network has trained with the shares of one company from NSE, and then the network has anticipated five different companies from both NSE and NYSE. CNN outperformed all other models, predicting NYSE even though it was the only one trained in NSE data. What helped CNN to do this is that both the stock markets share some typical internal dynamics. The authors compared the results with the ARIMA model. They found that neural networks are superior to the current linear model (ARIMA).

In the paper (Chen et al. 2018), a new forecasting system is proposed for the Chinese stock market. The researchers were able to extract the features from big data without referring to previous forecast data. They suggested further improving this predictive performance using a combination of a deep-learning equity-based stock forecasting model, the automatic coding device, and the restricted Boltzmann device. Besides, they compared three conventional artificial neural networks, (1) the neural network for the radial basis function, (2) the extreme learning machine, and (3) the neural network for posterior proliferation. Using highfrequency data to examine the predictive performance of deep learning in their empirical analysis, they tested three groups of different size samples to validate their observations. The results summarized that the deep learning method for predicting stock index futures outperforms backward spread, the extreme learning machine, the radial basis function's neural network function in its degree of suitability, and directional predictive accuracy. They also found that increasing the amount of data raises predictive performance. This indicates that deep learning captures the non-linear features of transaction data and can serve as a powerful tool for forecasting equity index futures for financial market investors.

In the paper (Yarovaya et al. 2020a), Yarovaya et al. presented new empirical evidence on the cryptocurrency market during the coronavirus pandemic. They collected the hourly closing prices of four currencies that are among the most traded in the cryptocurrency market: US dollar, euro, Japanese yen, and the South Korean won, where they analyzed herding in the cryptocurrency market using quantitative methods at hourly rates for the four currencies mentioned above, the results showed that COVID-19 does not amplify herding in cryptocurrency markets. Herding remains dependent on bull or bear market days in all markets studied but was not more potent in the COVID-19 period.

In the paper (Conlon et al. 2020), Due to the first negative noticeable impact of its kind on the economic situation because of Covid-19, they have studied the haven for digital currencies test the widely mooted haven properties of Tether, Ethereum, and Bitcoin from the perspective of international equity index investors, Tether succeeded in maintaining its currency peg to the US dollar during the COVID-19 disruptions, as it proved during testing that it was a natural haven for its investors, unlike both Bitcoin and Ethereum. Also, only investors affiliated with the Chinese CSI 300 Index reap modest downside risks.

In the paper (Yarovaya et al. 2020b), Larisa et al. have done a paper that summarizes, in particular, the actual impact of the Corona crisis on financial performance, as they presented a new approach that helps in assessing the economic conditions at present and perhaps in the future when any unexpected crises occur, as their approach stressed by focusing on four basic levels of information transmission: (1) the infection trigger (2) Media attention; (3) Indirect influence on financial markets; (4) Macroeconomic fundamentals, as their goal was to help other researchers to understand the impact of Corona on financial conditions clearly.

In the paper (Aloui et al. 2020), Donia et al. conducted a paper to assess the impact of COVID-19 crisis shocks on energy futures markets, especially oil and natural gas, using a structural VAR model with time-lapse variable coefficients and random changes (TVP-SVAR model); the results confirmed that oil and gas indicators Energy commodities are remarkably responsive to the COVID-19 
shock that varies over time due to fundamental, behavioral, and psychological factors.

The main gap rises by this research is how to make a forecasting model to figure out the effect of the different situations occurred by the COVID-19 pandemic. Find a powerful and precise model for predict the status of the stock marketing and other various business is complicated. Therefore, dealing with these difficult situations is not easy in order to know the status of stocks and predict their status with the extension of this pandemic. When it became clear that these exceptional circumstances have a significant impact on the purchasing values of commodities and stocks, they vary greatly from time to time and under unstable conditions. These problems need a system capable of compatibility to predict the changes that will occur due to this pandemic.

\section{Research methodology}

This paper aims to determine the most affected stock market in the GCC and predict its situation in the near time until the end of December 2020 by applying correlational analytics and forecasting techniques. Besides extracting hidden facts from visualizations that support the correlation results and arrives at the main objective of advising decision-makers to evade future financial risks. Therefore, three different datasets for GCC countries' COVID-19 confirmed cases, stock markets, and regional features to perform Correlation, Forecasting, and Visualization used, as revealed in Fig. 1. A forecasting model is proposed to show the main effects of the COVID-19 pandemic on stock marketing and various business. This helps manage the business during the spread of COVID-19 and make sure how to act with the different situations.

\subsection{Datasets \& visualizations}

The datasets were collected from the 'Trading Economies' website. The first one has 10 months' time-series records for GCC counties, namely the UAE, KSA, Qatar, Oman,
Kuwait, and Bahrain. The records indicated the daily confirmed cases of COVID-19 virus for each country. The second one has 10 months' time-series records for the same countries. However, the records indicated the stock market's daily gained points for each country. At the same time, the third one has six records and three features. The records defined the GCC countries, and the features indicate the COVID-19 summary and some regional indicators. Table 1 shows the description of the whole dataset features. The analytics focuses on papering the correlation between the number of COVID-19 confirmed cases and the number of points earned by the stock market from January to October 2020.

A Tableau is a powerful tool that helps in simplifying datasets into easily understandable visualizations. In describing the distributions of the regional indicators Total Cases, Cases per million, Population, GDP, and GB, Tableau will be used to implement different indicators for all GCC countries where the Interpretations of these visualizations are going to serve to extract the differentiation between each country.

\subsection{Forecasting}

The first dataset contains the time series of COVID-19 cases for 10 months. Hence, the Prophet forecasting model will be applied to predict the cases for the near time until the end of December. The Prophet model is a time series forecasting model that can handle a standard feature and is designed to have intuitive parameters that can be changed without needing to go through details (Yenidogan et al. 2019). Moreover, the model uses an analyzable time series model with three parameters; trend, seasonality, and holidays. Where these parameters are combined in the given equation:

$y(t)=g(t)+s(t)+h(t)+\in t$, where $g(t)$ is the piecewise linear or logistic growth curve for modeling non-periodic changes in time series, $s(t)$ is the periodic changes, $h(t)$ is the effects of holidays (user-provided) with irregular schedules, and $\in t$ is the error term that accounts for any unusual changes not accommodated by the model.

Fig. 1 Methodology diagram

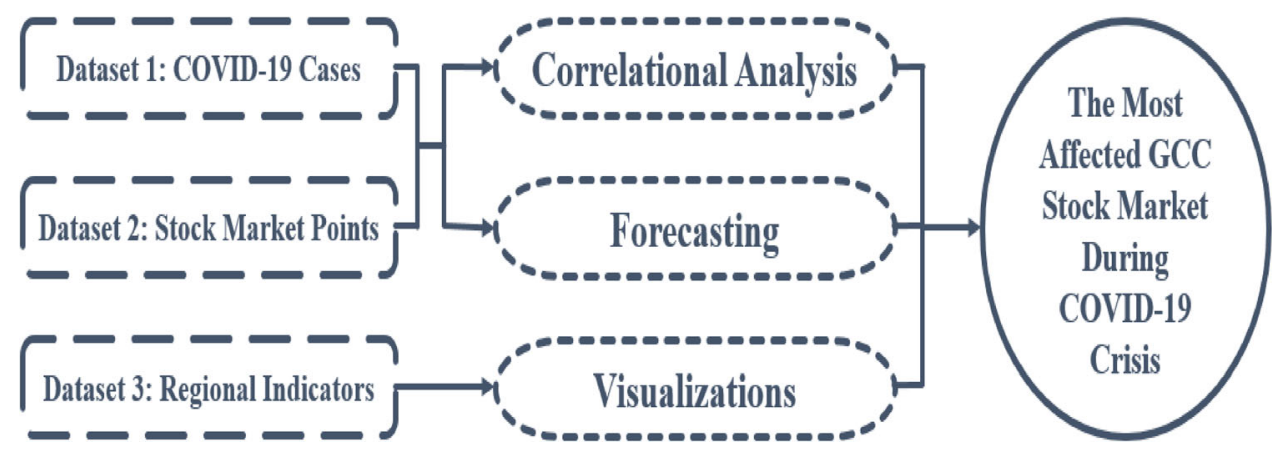


Table 1 Description of third dataset features

\begin{tabular}{ll}
\hline Feature & Description \\
\hline 1. Cases per million & The number of cases per million humans, based on the population of the country \\
2. Population & The total citizens of the country, which was retrieved from 2019 last statistic \\
3. GDP & Gross domestic product is the monetary measure of the market value of the goods and services produced in 2019
\end{tabular}

The model requires to specify some features to perform the forecasting task, and Table 2 shows the chosen features for a daily seasonality model (without using holidays parameter) and a brief description for each one.

The model will be fitted according to the holdout splitting method, where the training set is $70 \%$ of the dataset, and the test set is $30 \%$ of the dataset. Finally, the model performance for each country is going to be measured through using the following metrics:

- $R^{2}=\frac{\sum\left(\widehat{y_{i}}-\bar{y}\right)^{2}}{\sum\left(y_{i}-\bar{y}\right)^{2}}$, where $\widehat{y_{i}}$ is the predicted value and $\bar{y}$ is the mean of the real values.

- $M S E=\frac{1}{N} \sum\left(y_{i}-\widehat{y}_{i}\right)$, where $N$ is the number of samples, $\widehat{y_{i}}$ is predicted value, and $y_{i}$ is the actual value.

- $M A E=\frac{1}{N} \sum\left|y_{i}-\widehat{y}_{i}\right|$, where $N$ is the number of samples, $\widehat{y_{i}}$ is predicted value, and $y_{i}$ is the actual value.

This model will be performed to predict the average COVID-19 cases for each month of the period from October to December, which can be used in the following correlational analysis section.

\subsection{Correlational analysis}

This step is meant to explore the relationship between two variables; the daily COVID-19 confirmed cases and the daily stock market gained points from January to December. The linear correlation equation is a method for extracting hidden relationships between two attributes from the dataset (Senthilnathan 2019), which allowed us to predict the values of a dependent variable (stock market points) given an independent variable (COVID-19 cases). In this equation, it should be considered that variables fall in the standard distribution; hence the ladder of power can be applied to re-express both variables' values, in which both ranges become close to each other, and un-normal distributions become normal (Carpentier 2016).

Before building the equation, it is necessary to check the linear association between the variables; thus, the first value to be computed is the correlation coefficient (R) (Asuero et al. 2006). This value indicates the strength of the linear association between the variables, and to quantify it between two variables $\mathrm{X}$ and $\mathrm{Y}$, can be given as:

$$
R=\frac{n\left(\sum X Y\right)-\left(\sum X\right) \cdot\left(\sum Y\right)}{\sqrt{n\left(\sum X^{2}\right)-\left(\sum X\right)^{2}} \cdot \sqrt{n\left(\sum Y^{2}\right)-\left(\sum Y\right)^{2}}}
$$

,where $\mathrm{n}$ is the number of observations.

The correlation can be classified based on the direction value of the correlation factor, where the positive trend indicates to have a positive association, and the negative trend indicates to have a negative association. The range of correlation coefficient $(\mathrm{R})$ lies between $(-1$ and +1$)$ (Schneider et al. 2010), where the values can be interpreted as shown in Table 3.

The correlation can help provide a linear regression model that predicts the dependent variable's values with the independent variable (Palmer and Connell 2009). Moreover, the correlation coefficient (r)'s squared value indicates how accurate the dependent variable's predicted value is concerning the given independent variable (Schober and Schwarte 2018). In this work, the linear regression model of the dependent variable and the independent variable given as:

$$
(\text { Stock Market Points })=\beta 0+\beta 1 .(\text { Covid }-19 \text { Cases })
$$

Table 2 The chosen features of the model with a brief description

\begin{tabular}{lll}
\hline Feature & Description & Chosen value \\
\hline Period & Same periods of each season & 1 \\
Fourier order & Indicates how the model start representing the curve & 15 \\
\hline
\end{tabular}


Table 3 Interpretation of correlation coefficient

\begin{tabular}{lll}
\hline Negative direction values & Positive direction values & Correlation category \\
\hline$(0,-0.2)$ & $(0,0.2)$ & Very week \\
$(-0.2,-0.3)$ & $(0.2,0.3)$ & Week \\
$(-0.3,-0.5)$ & $(0.3,0.5)$ & Moderate \\
$(-0.5,-0.7)$ & $(0.5,0.7)$ & Strong \\
$(-0.7,-1)$ & $(0.7,1)$ & Very strong \\
\hline
\end{tabular}

, where $\beta 0$ is the intercept of the used data and $\beta 2$ is the slope of the used data.

This equation will be used to predict the average stock market points for each week of the period from October to December, using the forecasting results of COVID-19 cases. Finally, the results can help summarize the most dramatic stock market situation in the near time of the COVID-19 pandemic.

\section{Experimental results}

The experiments were carried out using a (Dell) computer with $3.20 \mathrm{GHz}$ CPU Intel Core(TM) i7-8700 and memory of $16 \mathrm{~GB}$. The operating system is windows 10 , and the software used is Python (3.7) through the Google Colab environment. Logically, the knowledge extraction starts with initial assumptions, then supports it by provident evidence. Thus it becomes fundamental knowledge that can be used to think about new insights.

The map in Fig. 2 indicates the population value (per million) for all GCC countries, which showed that KSA has the highest population compared with the other countries.

The bar chart in Fig. 3 indicates the GDP (Billion US) for all GCC countries, showing that KSA also has the highest GDP compared with the other countries.

The bar chart in Fig. 4 indicates the total confirmed COVID-19 cases for all GCC countries, which showed that KSA also has the highest cases of COVID-19 compared with the other countries.

The bar chart in Fig. 5 indicates the COVID-19 cases per million populations for all GCC countries, which

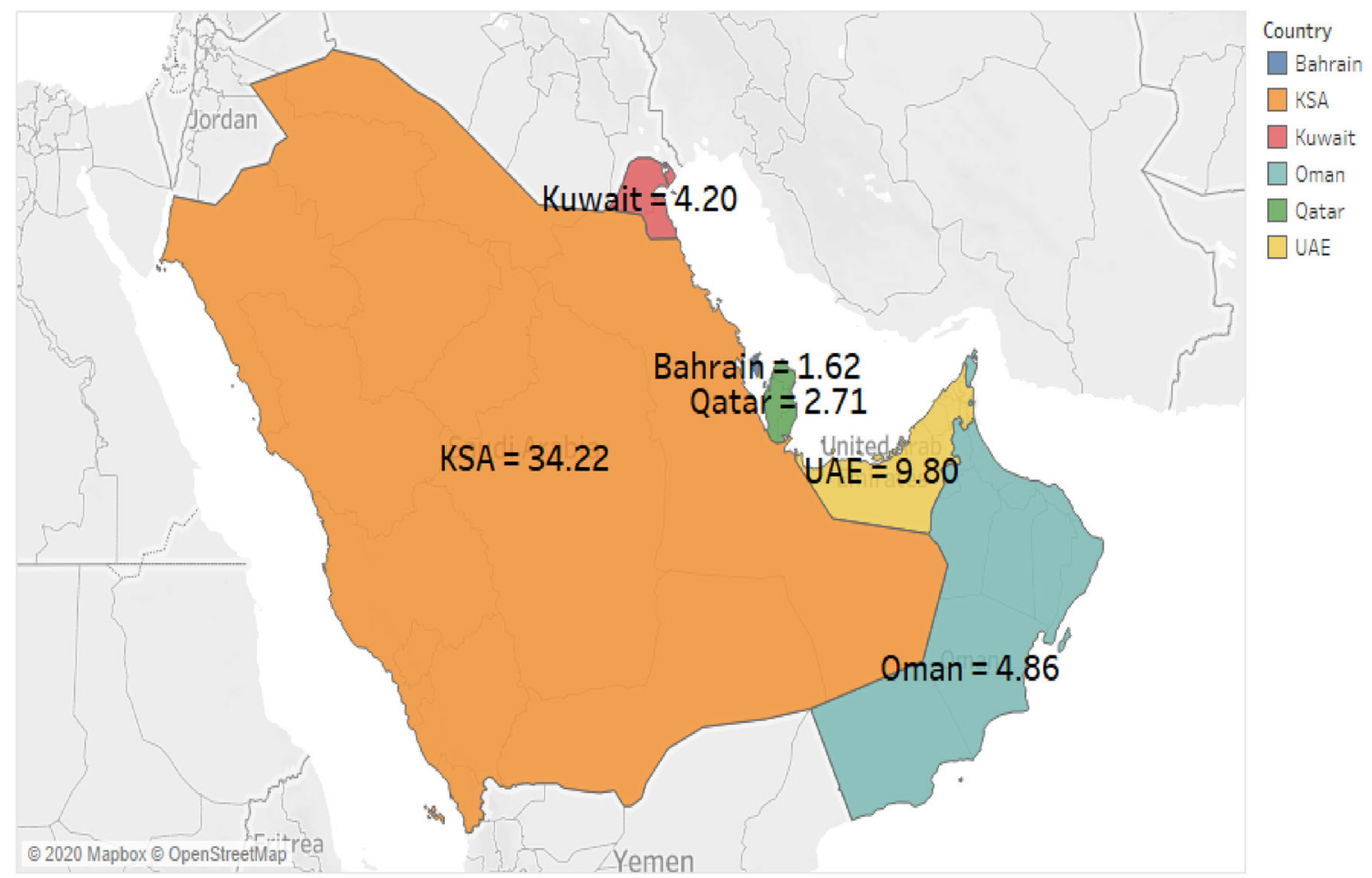

Fig. 2 The population map of GCC countries 
Fig. 3 The GDP of GCC countries

Fig. 4 COVID-19 total cases of GCC countries

Fig. 5 COVID-19 confirmed cases per million of GCC countries
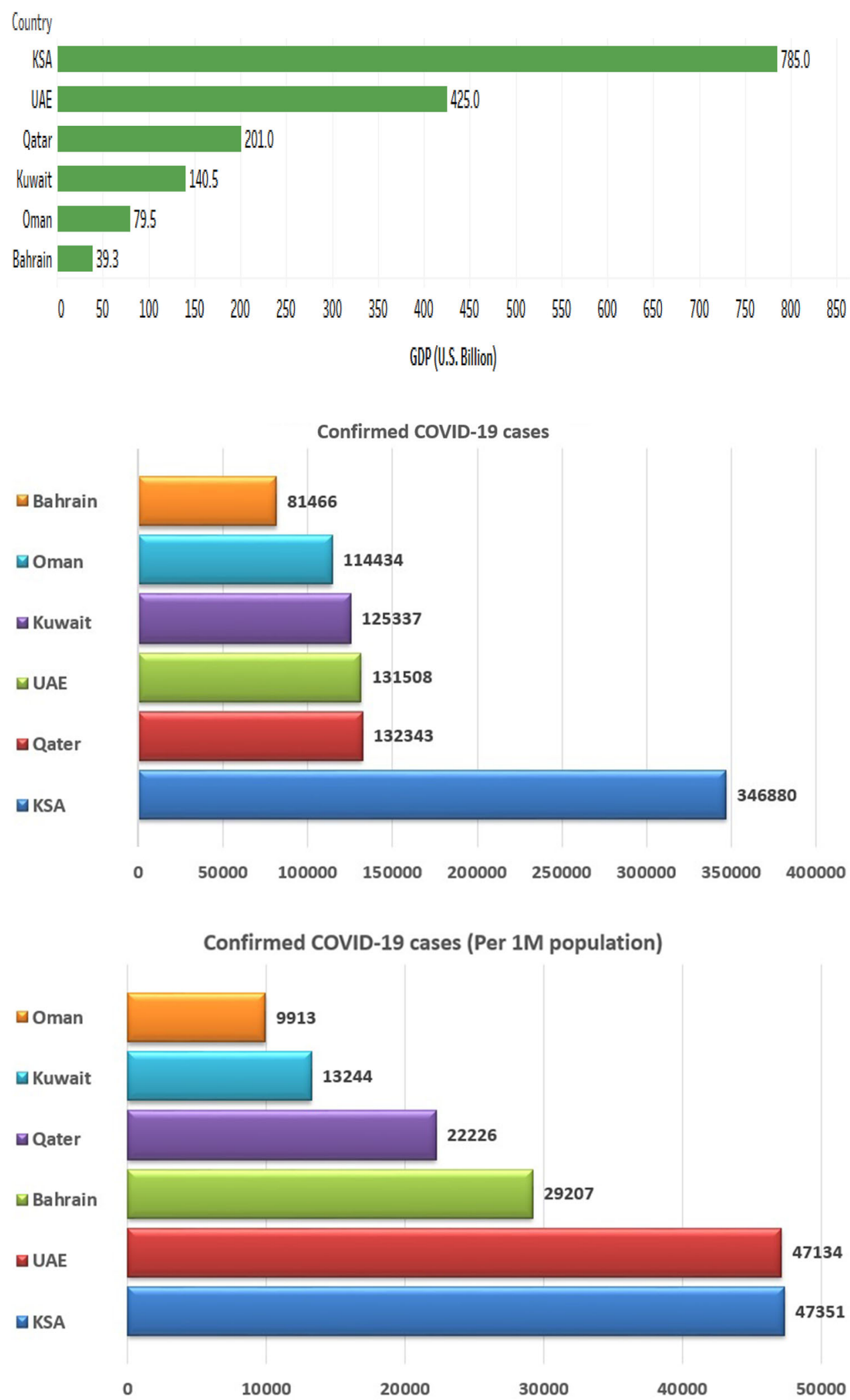

showed that Bahrain and Qatar populations are the most affected by the COVID-19 pandemic compared with the other countries.
The first experiment has been performed on the dataset of COVID-19 cases for each GCC country separately, applying the Prophet forecasting model, where the results 
Table 4 Mode performance for all GCC countries

\begin{tabular}{llll}
\hline Country & $\mathrm{R}^{2}$ & MSE & MSA \\
\hline UAE & 0.92 & 179,103 & 364 \\
KSA & 0.95 & 189,502 & 390 \\
Qatar & 0.82 & 99,477 & 197 \\
Oman & 0.88 & 139,401 & 245 \\
Kuwait & 0.86 & 133,428 & 231 \\
Bahrain & 0.89 & 163,507 & 283 \\
\hline
\end{tabular}

in Table 4 showed that the model fit on the dataset very well.

The model predicted values that could be considered successful in the near time from October to December, where the monthly average cases have been calculated based on the daily forecasting. The expected average cases were specified for the next two months for each GCC country, and Table 5 shows the range of cases results.

The results indicated that the increase in COVID-19 cases will continue in Bahrain and UAE, where the highest rate of increase is in UAE, and the lowest rate of increase is in KSA.

- The linear regression model to predict the UAE stock market points based on COVID-19 cases is given as:

$($ Stock Market Points $)=5.53-0.10($ Covid -19 Cases $)$, where the correlation factor $r=-0.78$.

The equation shows a robust negative relationship between the stock market points and COVID-19 cases; hence, if UAE confirmed a high number of COVID-19 cases, the stock market points would decrease.

- The linear regression model to predict the KSA stock market points based on COVID-19 cases is given as:

$($ Stock Market Points $)=6.03-0.08($ Covid -19 Cases $)$, where the correlation factor $r=-0.85$.

The equation shows a strong negative relationship between the stock market points and COVID-19 cases; hence, if KSA confirmed a high number of COVID-19 cases, the stock market points would decrease.
- The linear regression model to predict the Qatar stock market points based on COVID-19 cases is given as:

$($ Stock Market Points $)=6.32-0.08($ Covid -19 Cases $)$, where the correlation factor $r=-0.88$.

The equation shows a strong relationship between the stock market points and COVID-19 cases; hence, if Qatar confirmed a high number of COVID-19 cases, the stock market points would decrease.

- The linear regression model to predict the Oman stock market points based on COVID-19 cases is given as:

$($ Stock Market Points $)=5.28-0.07($ Covid -19 Cases $)$, where the correlation factor $r=-0.87$.

The equation shows a robust negative relationship between the stock market points and COVID-19 cases; hence, if Oman confirmed a high number of COVID-19 cases, the stock market points would decrease.

- The linear regression model to predict the Kuwait stock market points based on COVID-19 cases is given as:

$($ Stock Market Points $)=5.74-0.13($ Covid -19 Cases $)$, where the correlation factor $r=-0.90$.

The equation shows a robust negative relationship between the stock market points and COVID-19 cases; hence, if Kuwait confirmed a high number of COVID-19 cases, the stock market points would decrease.

- The linear regression model to predict the Bahrain stock market points based on COVID-19 cases is given as:

$($ Stock Market Points $)=4.41-0.07($ Covid -19 Cases $)$, where the correlation factor $r=-0.88$.

The equation shows a robust negative relationship between the stock market points and COVID-19 cases; hence, if Bahrain confirmed a high number of COVID-19 cases, the stock market points would decrease.

Gulf markets indices declined in the last period from January to October as the following; UAE stock market points decreased by -0.013933333 , KSA stock market points decreased by -0.006655518 , Qatar stock market points decreased by -0.022006689 , Oman stock market
Table 5 COVID-19 forecasting results

\begin{tabular}{lllrrrr}
\hline Country & UAE & KSA & Qatar & Oman & Kuwait & Bahrain \\
\hline November & $1700-2000$ & $0-300$ & $100-400$ & $0-750$ & $500-900$ & $175-675$ \\
December & $1800-2200$ & $0-50$ & $0-300$ & $0-550$ & $450-850$ & $250-750$ \\
\hline
\end{tabular}


points decreased by -0.015050167 , the Kuwait stock market points decreased by -0.028533333 , and Bahrain stock market points decreased by -0.006166667 . From these results, the Kuwait stock market is the most affected stock market from the GCC markets during the COVID-19 pandemic. Moreover, Bahrain has registered the highest rate of COVID-19 cases per million populations. These facts enhance the fact that COVID-19 harmed the GCC stock markets. Based on the prediction results from the correlational analysis, it was shown that the Gulf markets indices would decline in the next 2 months until End-December. Finally, it can be summarized that the decisionmakers of the Bahrain government must take all possible actions to reduce these losses and work on new procedures to eliminate the harms of the COVID-19 pandemic.

\section{Conclusion}

According to the economic effects caused by the COVID19 pandemic, the GCC stock market indices have decreased over time. This paper aims to determine the most affected stock market by COVID-19 among GCC stock markets and examine the factors that may increase this effect, tracking the expected future events. This work's importance lies in the recommendations that can be concluded from the analytics results, which can mitigate the financial impacts by taking the proper actions to reduce them. This work aimed at papering the relationship between the COVID-19 cases and the stock market points for all GCC countries; UAE, KSA, Qatar, Oman, Kuwait, and Bahrain. The datasets have found that the stock market points are strongly correlated with the COVID-19 cases in each country. Once the country registers a higher number of cases, the stock market point would be decreased.

Moreover, the Prophet mode for forecasting has shown that Bahrain was the most affected by the COVID-19 pandemic, with 47,351 confirmed cases by million populations. The stock market of Kuwait was the most affected, also with average losses of -0.28 . In the near time, the losses would be increased in all markets, wherein the next two months, Bahrain stock markets would be the most affected by the pandemic with losses -0.35 . From the results of this work, it can be stated that decision-makers of the Bahrain stock market and the government have to take proper actions to mitigate the financial impacts.

\section{Funding No funding.}

\section{Declarations}

Conflict of interest The authors declared that there is no conflict of interest.

\section{References}

Abualigah L, Diabat A, Sumari P, Gandomi AH (2021) A novel evolutionary arithmetic optimization algorithm for multilevel thresholding segmentation of covid-19 ct images. Processes 9(7): 1155

Adekoya OB, Oliyide JA, \& Tiwari AK (2021) Risk transmissions between sectoral Islamic and conventional stock markets during COVID-19 pandemic: What matters more between actual COVID-19 occurrence and speculative and sentiment factors? Borsa Istanbul Review

Al Refai H, Zeitun R, Eissa MAA (2021) Impact of global health crisis and oil price shocks on stock markets in the GCC. Finance Res Lett. https://doi.org/10.1016/j.frl.2021.102130

Alber N, Arafa A (2020) The impact of coronavirus pandemic on stock market return: the case of the MENA region. Int $\mathrm{J}$ Econ Finance. https://doi.org/10.5539/ijef.v12n12p100

Alber N, Saleh A (2020) The impact of covid-19 spread on stock markets: the case of the GCC countries. Int Bus Res 13(11):1-16

Aloui D, Goutte S, Guesmi K, Hchaichi R (2020) COVID 19's impact on crude oil and natural gas S\&P GS indexes. SSRN Electron J. https://doi.org/10.2139/ssrn.3587740

Al-qaness MAA, Ewees AA, Fan H, Abd El Aziz M (2020) Optimization method for forecasting confirmed cases of COVID-19 in China. J Clin Med 9(3):674

Asuero AG, Sayago A, González AG (2006) The correlation coefficient: an overview. Crit Rev Anal Chem 36(1):41-59

Baker SR, Bloom N, Davis J, Kost K, Sammon M, Viratyosin T (2020) The unprecedented stock market reaction to covid-19. Pandemics Long-Run Eff Eff 1(DP14543):33-42

Bekhet HA, Matar A, Yasmin T (2017) CO2 emissions, energy consumption, economic growth, and financial development in GCC countries: dynamic simultaneous equation models. Renew Sustain Energy Rev 70:117-132

Ben Amar A, Bélaïd F, Ben Youssef A, Guesmi K (2020) Connectedness among regional financial markets in the context of the COVID-19. Appl Econ Lett. https://doi.org/10.1080/ 13504851.2020 .1854434

Carpentier N (2016) Beyond the ladder of participation: an analytical toolkit for the critical analysis of participatory media processes. Javnost 23(1):70-88

Chen L, Qiao Z, Wang M, Wang C, Du R, Stanley HE (2018) Which artificial intelligence algorithm better predicts the Chinese stock market? IEEE Access 6(8):48625-48633

Conlon T, Corbet S, McGee RJ (2020) Are cryptocurrencies a safe haven for equity markets? An international perspective from the COVID-19 pandemic. Res Int Bus Financ 54(May):101248

Davison RH (1960) Where is the Middle East? Foreign Aff 38(4):665

Gormsen NJ, Koijen RS (2020) Coronavirus: impact on stock prices and growth expectations. Rev Asset Pricing Stud 10(4):574-597

Gupta R, Pandey G, Chaudhary P, Pal SK (2020) SEIR and regression model based COVID-19 outbreak predictions in India. medRxiv. https://doi.org/10.1101/2020.04.01.20049825

Hiransha M, Gopalakrishnan EA, Menon VK, Soman KP (2018) NSE stock market prediction using deep-learning models. Procedia Comput Sci 132(Iccids):1351-1362

Li H, Liu S-M, Yu X-H, Tang S-L, Tang C-K (2020) Coronavirus disease 2019 (COVID-19): current status and future perspective. Int J Antimicrob Agents 2019:105951

Liu H, Manzoor A, Wang C, Zhang L, Manzoor Z (2020) "The covid19 outbreak and affected countries stock markets response." Int J Environ Res Publ Health 17:1-19

McKibbin WJ, Fernando R (2020) The global macroeconomic impacts of COVID-19: seven scenarios. SSRN Electron J. https://doi.org/10.2139/ssrn.3547729 
Mottahedi A, Sereshki F, Ataei M, Qarahasanlou AN, Barabadi A (2021) Resilience analysis: a formulation to model risk factors on complex system resilience. Int J Syst Assur Eng Manag. https://doi.org/10.1007/s13198-021-01131-w

Okorie DI, Lin B (2021) Adaptive market hypothesis: the story of the stock markets and COVID-19 pandemic. N Am J Econ Finance 57:101397

Palmer PB, Connell DGO (2009) Regression analysis for prediction: understanding the process. Cardiopulm Phys Ther J 20(3):23-26

Reyad O (2020) "Novel coronavirus COVID-19 strike on Arab countries and territories: a situation report I. (arXiv: 2003.09501v1 [cs.CY]).” arXiv Comput Sci., 1-3

Ronald Doni A, Sasi Praba T, Murugan S (2021) Weather and population based forecasting of novel COVID-19 using deep learning approaches. Int J Syst Assur Eng Manag. https://doi.org/ 10.1007/s13198-021-01272-y

Rosenzweig E (2015) Successful user experience: strategies and roadmaps. What is user experience? Elsevier, pp 1-344

Rubbaniy G, Khalid AA, Umar M, Mirza N (2021) European stock markets' response to COVID-19, lockdowns government response stringency and central banks' interventions. Lockdowns Gov Response String Cent Banks' Interv (February 14, 2021). https://doi.org/10.2139/ssrn.3785598

Sadiq M, Hsu CC, Zhang Y, Chien F (2021) COVID-19 fear and volatility index movements: empirical insights from ASEAN stock markets. Environ Sci Pollut Res. https://doi.org/10.1007/ s11356-021-15064-1

Schneider A, Hommel G, Blettner M (2010) Lineare regressionsanalyse-teil 14 der serie zur bewertung wissenschaftlicher publikationen. Dtsch Arztebl 107(44):776-782

Schober P, Schwarte LA (2018) Correlation coefficients: appropriate use and interpretation. Anesth Analg 126(5):1763-1768

Senthilnathan S (2019) Usefulness of correlation analysis. SSRN Electron J. https://doi.org/10.2139/ssrn.3416918

Sharma DK, Hota HS, Brown K, Handa R (2021) Integration of genetic algorithm with artificial neural network for stock market forecasting. Int J Syst Assur Eng Manag. https://doi.org/10.1007/ s13198-021-01209-5
Shehab M, Daoud MS, AlMimi HM, Abualigah LM, Khader AT (2019) Hybridising cuckoo search algorithm for extracting the ODF maxima in spherical harmonic representation. Int J BioInspired Comput 14(3):190-199

Sherif M (2020) The impact of coronavirus (COVID-19) outbreak on faith-based investments: an original analysis. J Behav Exp Finance 28:100403

Sohrabi C et al (2020) World health organization declares global emergency: a review of the 2019 novel coronavirus (COVID19). Int J Surg 76(February):71-76

Sumari P, Syed SJ, Abualigah L (2021) A novel deep learning pipeline architecture based on CNN to detect covid-19 in chest X-ray images. Turkish J Comput Math Edu (TURCOMAT) 12(6):2001-2011

Szczygielski JJ, Bwanya PR, Charteris A, Brzeszczyński J (2021) The only certainty is uncertainty: an analysis of the impact of COVID-19 uncertainty on regional stock markets. Finance Res Lett. https://doi.org/10.1016/j.frl.2021.101945

Yarovaya L, Matkovskyy R, Jalan A (2020) The effects of a 'black swan' event (COVID-19) on herding behavior in cryptocurrency markets: evidence from cryptocurrency USD, EUR, JPY and KRW markets. SSRN Electron J. https://doi.org/10.2139/ssrn. 3586511

Yarovaya L, Brzeszczynski J, Goodell JW, Lucey BM, Lau CK (2020) Rethinking financial contagion: information transmission mechanism during the COVID-19 pandemic. SSRN Electron J. https://doi.org/10.2139/ssrn.3602973

Yenidogan I, Cayir A, Kozan O, Dag T, and Arslan C (2018) "Bitcoin forecasting using ARIMA and PROPHET," UBMK 2018-3rd Int Conf Comput Sci Eng. no. February 2019, pp. 621-624

Yousri D, Abd Elaziz M, Abualigah L, Oliva D, Al-Qaness MA, Ewees AA (2021) COVID-19 X-ray images classification based on enhanced fractional-order cuckoo search optimizer using heavy-tailed distributions. Appl Soft Comput 101:107052

Publisher's Note Springer Nature remains neutral with regard to jurisdictional claims in published maps and institutional affiliations. 